\section{Alcoholic Cardiomyopathy}

Excessive drinking of alcohol can produce profound changes of myocardial function and structure. ${ }^{1-9}$ Investigations of beriberi heart disease in occidentals in $1946^{10}$ suggested that alcohol had no direct effect on the heart but that the symptoms were the result of the thiamine and other vitamin deficiencies from which these patients suffered. The possibility of a direct effect of alcohol on the myocardium then received little attention until 1960, when a clinical distinction between heart disease of chronic spirit drinkers and alcoholic beriberi heart disease was studied. ${ }^{11}$ More recent clinical experience has shown ${ }^{4}$ that nutritional deficiencies have an important role in only a minority of cases. Most patients in developed countries who consume large quantities of alcohol and go into congestive failure are well nourished and respond to prolonged bed rest and abstinence from alcohol. ${ }^{12}$

This clinical observation has led G. E. Burch and his co-workers ${ }^{13}$ recently to investigate whether or not alcohol directly damages the myocardium. These authors exposed 55 mice to long-term, unrestricted intake of alcohol in various forms, this being the only fluid the animals were allowed. Ten additional mice-acting as controls-received water and no alcohol. All mice were given free access to a balanced commercial laboratory food. The test animals were divided into four groups, each consuming various concentrations and volumes of alcoholic beverage. Group 1, consisting of 25 mice, was given beer ( $5 \%$ alcohol). The remaining groups each consisted of ten mice. Group 2 was given 5\% ethyl alcohol, group $320 \%$ ethyl alcohol, and group 4 commercially available wine $(20 \%$ alcohol). The animals were killed after six months and each group showed an increase in weight. The mice drinking wine gained least and those drinking beer and plain alcohol gained weight throughout the duration of the experiment.

The hearts of the mice fed on alcoholic drink showed focal damage of the myocardium consisting of areas of hydropic degeneration and loss of striation in some muscle fibres. Interstitial oedema and shrunken, irregular nuclei, were also observed. Round-cell infiltration and fibroblastic proliferation were occasionally seen. All these changes were observed in the ventricular myocardium, particularly towards the endocardium. Electron-microscopic examination showed alteration in $56 \%$ of the animals. It consisted of accumulation of lipid, fragmentation of myofibrils, and other changes. Histochemical studies also disclosed alterations in $35 \%$ of the hearts.

These experiments showed that myocardial damage can be produced in mice as a direct result of alcohol, that the changes produced were irrespective of the type or strength of alcohol to which the mice had been subjected, and that they were similar to those described in human hearts. ${ }^{6-8}$ Thus there can now be little doubt that excessive consumption of alcohol does have a deleterious effect on the heart.

Unfortunately no pathonomonic criteria have so far been described for recognizing alcoholic cardiomyopathy. The electron-microscope appearances, except for minor characteristic changes possibly due to alcohol, have been likened to those occurring in anoxia. ${ }^{6}$ But similar changes have also been described ${ }^{14}$ in primary myocardial disease from which alcohol as a cause can be excluded.

1 Brigden, W., Lancet, 1957, 2, $1179,1243$.

2 Evans, W., British Heart fournal, 1959, 21, 445.

3 Burch, G. E., and Walsh, J. J., American fournal of Cardiology, 1960, 6, 864 .
4 Brigden, W., and Robinson, J., British Medical fournal, 1964, 2, 1283.

5 Heggtveit, H. A., American Heart fournal, 1965, 69, 422.

- Heggtveit, H. A., American Heart fournal, 1965, 69, 422.

7 Alexander, C. St S., American fournal of Medicine, 1966, 41, 229.

7 Alexander, C. S., American Fournal of Medicine, 1966,

8 Alexander, C. S., British Heart fournal, 1967, 29, 200.

10 Burch, G. E., and DePasquale, N. P., Cardiologia, 1968, 52, 48. fournal of the American Medical Association, 1946, 131, 717. 11 Evans, W., American Heart fournal, 1961, 61, 556.

12 Burch, G. E., Walsh, J. J., and Black, W. C., fournal of the American Medical Association, 1963, 183, 81.

13 Burch, G. E., Harb, J. M., Colcolough, H. L., and Tsui, C. Y., Fohns Hopkins Medical fournal, 1971, 129, 130.

14 Bulloch, R. T., and Murphy, M. L., Circulation, Supplement II, 1967, 35 and 36,78 .

\section{Tourniquet Techniques}

Sterling Bunnell, the father of modern hand surgery, is reputed to have said that operating on a hand without a tourniquet is like trying to fix a watch in a bottle of ink. Nevertheless the tourniquet can do damage, and the surgeon needs to balance the immense benefit of the bloodless field against injury to the limb (caused by anoxia) from direct pressure of the pneumatic cuff and injury caused by postoperative haematoma in the wound from the reactive hyperaemia which follows release of the tourniquet. After release of a tourniquet that has been in position for two hours the acidotic changes in the limb take about half an hour to disappear, and it has been suggested that two hours' ischaemia represents the upper limit of safety. ${ }^{1}$

When applying a tourniquet after exsanguination of the arm with an Esmarch bandage it is common practice to inflate the cuff to $250 \mathrm{~mm} \mathrm{Hg}$ in an adult and $200 \mathrm{~mm} \mathrm{Hg}$ in a child. With a pneumatic cuff serious local pressure effects on nerves and vessels are rare, but pinching and bruising of the skin are only too common. A. E. Flatt ${ }^{2}$ reports one case of a child who sustained a circumferential alcohol burn of the skin at the level of the distal edge of a tourniquet cuff which had become saturated with the alcohol used in preparing the skin for operation. Minor damage by the cuff to the skin can be reduced to a minimum by wrapping sufficient orthopaedic wool around the upper arm beneath the cuff. Proper bandaging and elevation of the arm before release of the tourniquet help to reduce bleeding into the wound. Measures to avoid venous congestion in a limb on release of the cuff include rapid release of the pressure, immediate removal of the cuff, and, what is most important, immediate removal of the wool wrapped round the arm beneath it.

The modern gas-filled pneumatic cuff is simple to inflate and the pressure is recorded on a dial, but nerve damage has followed a fault in the instrument, and Flatt recommends that such machines should be calibrated regularly against a mercury manometer. He finds that $95 \%$ of operations on the hand can be completed comfortably in less than two hours, and he considers that this tourniquet time is safe. Upper limbs were rendered ischaemic for more than two hours in 60 of his patients of various ages, and in none of them were there clinical signs of damage. It is commonly accepted that a child's arm can be rendered ischaemic with safety for $2 \frac{1}{2}$ hours, and a bloodless field for this length of time is necessary for complicated procedures. When operating with an experienced consultant anaesthetist the tourniquet time for the arm in adults may be reduced, and a reasonably dry field maintained, by the induction of controlled hypotension shortly before the tourniquet is removed, the low blood pressure being maintained until bandaging is completed. With this technique 
generalized oozing of blood is much reduced, and those vessels requiring ligature are displayed.

1 Wilgis, E. F., fournal of Bone and foint Surgery, 1971, 53a, 1343.

2 Flatt, A. E., Archives of Surgery, 1972, 104, 190.

\section{Progress on Pensions}

New proposals to modify the N.H.S. Superannuation Scheme have recently been published by the Joint Superannuation Consultative Committee. The changes suggested are broadly similar to those put to employees in other parts of the public sector, for instance, civil servants, teachers, and local authority staff.

The B.M.A. has been pressing for improvements for doctors for some time now ${ }^{1}$ and these proposals, summarized in the Supplement (p. 39), will be studied carefully by the profession. They fall into three categories: those wholly acceptable to the Association; those which are an improvement on the existing provisions but still compare unfavourably with the benefits available in good occupational schemes in the private sector; and those which are plainly unsatisfactory. The most important of the latter is the proposal to increase members' contributions to the scheme from 6 to $6 \frac{3}{4} \%$ of pensionable income.

The most beneficial alterations are the change in the basis for the calculation of benefits for salaried employeespensions for independent contractors are still under separate review-from an average of annual pensionable income over the last three years of service to an average over the last twelve months. This is obviously significant, particularly in an inflationary period. Then there is the granting of immediate life cover under the Scheme for all members regardless of service. An improvement which in any case will soon be mandatory in all approved occupational pension schemes is the introduction of complete preservation of benefits after the completion of five years' service. Other changes for the better are the increases made in children's benefits payable on the death of a member and the option which will now be available to a doctor who returns to the N.H.S. after a period of employment elsewhere to include his first period of service as pensionable.

Ill-health retirement benefits and widows' pensions have also been improved though these benefits will only be payable after the completion of five years' service. The widows' pension is now to be one-half of the member's pension-this compares with the existing benefit of one-thirdand the lump sum benefit payable in respect of a married man, either on death or retirement will no longer be reduced from $3 / 80$ th to $1 / 80$ th of his pensionable salary for each year of service. This change for widows, however, will concern future service only, so the benefits for many members will continue to be unsatisfactory. In any event, the ill-health retirement pension on which the widows' pension on death in service is based will still take only limited account of the prospective service of a member, whereas in a good occupational scheme full account of this prospective service to retirement is taken in calculating the benefits payable to a member who retires early because of illness. In addition, there seems no real reason why the cover for these particular benefits should not start as soon as a doctor begins to contribute. The cost of such benefits is lowest for the young contributor yet his need then is highest. An area of great controversy for doctors has been the abatement rule for reducing an individual's pension when he works on (part- or full-time) after the official retirement age. Though the B.M.A.'s objective, namely the complete abolition of abatement for doctors, has not yet been achieved, the new scheme will be better than the existing position.

The profession will be unhappy about the Government's intention to raise contributions, seeing this is an unreasonable price to exact for the improvements. Once again, the N.H.S. compares unfavourably when compared with occupational pension schemes in industry and even with other schemes in the public sector such as those of local authorities. A $6 \%$ contribution rate is comparatively rare in private industry and the B.M.A. considers that the benefits proposed by the Department could be satisfactorily met in a properly funded scheme ${ }^{2}$ by the existing rates of contribution payable by members and the Government. The N.H.S. scheme, however, is not established on a properly funded basis, but on the basis of a notional fund to which the Government credits interest from time to time at a rate recommended by the Government Actuary. Because this rate is linked to that available on British Government Securities, and has been for the last 25 years, the notional fund may not be in a position to meet the proposed increases in benefits without higher contributions. This, however, is not the fault of the members themselves who have had no influence whatsoever on investment policy. Had the assets of the N.H.S. scheme been invested on the basis of a funded scheme over the last 25 years the Association's view is that sufficient funds should now have been available to provide the better benefits and more. Thus no extra contributions from either side would have been required.

It appears that the Government proposes to discontinue the present system of notional funding as it would cease to credit the funds with a fixed level of employer contribution. The intention is presumably to reduce this contribution if the Government Actuary-after one of his periodic reviews-recommends that a lower contribution rate would be sufficient to fund the benefits to be provided. Increasing pressure is being put on the Government by other organizations such as the teachers' unions about the lack of proper funding of pensions in the public sector.

The Government's proposals are, in effect, a package deal. This is a pity because agreement has yet to be reached on the proper basis for calculating pensions of general practitioners and those part-time consultants who still have part of their pension based on their career earnings. In an era of roaring inflation a benefit based on career earnings is unsatisfactory unless some form of dynamism of pensions-the notional updating of career earnings to take account of inflation-or of earnings on which pensions are based is incorporated to offset the continuous fall in the value of money. Though the principle of dynamism has been accepted by the Department of Health, no satisfactory detailed scheme has yet been worked out and the B.M.A. is likely to make its acceptance of these package proposals conditional on this. Nevertheless, the package represents some progress on the present widely-criticized N.H.S. superannuation scheme.

$\begin{array}{ll}1 & \text { British Medical fournal, 1971, 1, } 622 . \\ 2 & \text { British Medical fournal, 1972, 1, } 325 .\end{array}$ 